\title{
Studies on the prekallikrein-bradykininogen system in liver disease
}

\author{
DAVID STEWART, LAURENCE M. BLENDIS, AND ROGER WILLIAMS ${ }^{1}$
}

From the Medical Research Council Group on Metabolism and Haemodynamics of Liver Disease, King's College Hospital Medical School, London

SYNOPSIS The plasma prekallikrein-bradykininogen system was studied in 45 patients with chronic of liver disease since its activation with increased liberation of kinin into the plasma could account for $A$ some of the clinical manifestations of cirrhosis, namely, vasodilatation, hypotension, and increased $\vec{O}$ capillary permeability.

A significant reduction in plasma bradykininogen was found in the cirrhotic patients as compared $\overrightarrow{-}$ with control groups of normal subjects and hospital inpatients. The mean plasma prekallikrein was not significantly different and only five patients with liver disease had reduced levels. The most likely explanation for the low plasma bradykininogen was impairment of synthesis by the cirrhotic $\stackrel{\oplus}{*}$ liver, the usually normal prekallikrein levels making the other possibility of increased activation of ${ }^{\text {N }}$ bradykininogen to bradykinin in the plasma less likely.

Bradykinin and other closely related, naturally occurring kinins, are known to have potent physiological and pharmacological properties including vasodilatation, lowering of the blood pressure, and increased permeability of the capillaries (Lewis, 1960). Although their exact role is uncertain there is increasing evidence that the plasma and tissue kinins may be of importance in the clinical manifestations of acute pancreatitis, endotoxin shock, angioneurotic oedema, as well as in the carcinoid syndrome (Colman, Mason, and Sherry, 1969a).

The properties mentioned could also account for the well known but as yet unexplained vasodilatation and hypotension of liver failure. We have also recently found evidence of an increase in capillary permeability in patients with cirrhosis when the plasma volume is increased, as it so often is when the spleen is enlarged (Blendis, Ramboer, and Williams, 1970). Normally, only small amounts of bradykinin are found in the plasma, the greater amount being present as the inactive plasma $a_{2}$ globulin-bradykininogen. Activation of the latter is brought about by the enzyme kallikrein, which is also normally present in an inactive form-prekallikrein. The latter can be activated by a number of substances including Hageman factor, permeability factor/dilute, trypsin, and antigen-antibody complexes.

'Correspondence: Dr Roger Williams, Liver Unit, King's College Hospital, London, SE5.

Received for publication 7 October 1971.
To date, however, few patients with liver disease

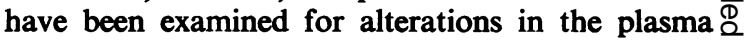
prekallikrein-bradykininogen system. Colman et al $\overrightarrow{\vec{B}}$ (1969a) found reduced plasma prekallikrein levels in $\frac{0}{3}$ six patients with cirrhosis consistent with increased $\bar{\partial}$ activation of the system whereas Carretero, Nasjletti, Inon, and Dohmen (1970) found no significant changes in the kinin and kininogenase activity of the? plasma in five patients with liver failure. The latter $\frac{5}{3}$ authors also found lower plasma prekallikrein in five patients with liver failure, and lower plasma bradykininogen levels which they attributed to impaired synthesis by the damaged liver. In this 9 paper we report measurements of plasma prekallik- $\frac{}{0}$ rein and bradykininogen in $\mathbf{4 5}$ patients with different varieties of chronic liver disease compared with $N$ control groups of normal subjects and hospital inpatients.

\section{Materials and Methods}

The control groups consisted of 23 normal subjects $\stackrel{\oplus}{+}$ and 25 hospitalized patients with a variety of medical $\frac{T}{0}$ conditions not involving the liver. The diagnoses of $\frac{\vec{D}}{\mathbb{D}}$ the 45 patients with chronic liver disease were as $\stackrel{?}{+}$ follows: alcoholic cirrhosis (11 cases), cryptogenic $\stackrel{\AA}{\varrho}$ cirrhosis (15 cases), active chronic hepatitis-usually with cirrhosis (19 cases), primary biliary cirrhosis ( $8 \Omega$ cases), and haemochromatosis ( 2 cases). Sixteen of 
these patients had both bradykininogen and prekallikrein levels measured.

Blood samples were taken without venous stasis and with minimal tissue injury into plastic syringes and expelled into heparinized plastic containers. The plasma was rapidly separated off and immediately cooled to $4^{\circ} \mathrm{C}$. Any glassware which came into contact subsequently with the plasma was siliconized (Siliclad, Clay-Adams).

\section{ESTIMATION OF PLASMA BRADYKINOGEN}

Plasma proteins were denatured by adding $0.2 \mathrm{ml}$ of plasma to $1.8 \mathrm{ml}$ of $0.2 \%$ acetic acid and boiling for 30 minutes. After cooling and neutralization with $1 \mathrm{~N}$ sodium hydroxide, $0.5 \mathrm{ml}$ of $0.2 \mathrm{M}$ tris buffer ( $p \mathrm{H} \mathrm{7.8)} \mathrm{containing} 400 \mu \mathrm{g}$ per $\mathrm{ml}$ of trypsin was added to activate the bradykininogen. The mixture was incubated at $37^{\circ} \mathrm{C}$ for 30 minutes after which reaction was stopped by rapidly ejecting the incubate into $5 \mathrm{ml}$ of hot $70 \%$ ethanol. An assay for kinin activity was then carried out using rat uterus and a dose-response curve obtained with synthetic pure bradykinin, histamine and serotonin activity being inhibited in the assay.

\section{ESTIMATION OF PLASMA PREKALLIKREIN}

The esterase activity of kallikrein towards certain synthetic substrates, namely benzoyl and tosyl (toluene sulphonyl) arginine methyl esters, can be used to measure the plasma prekallikrein content (Colman, Mattler, and Sherry, 1969b). Plasma samples were divided into two, one sample being incubated with a kaolin suspension to activate plasma prekallikrein to kallikrein whilst the other was left untreated.

Aliquots $(0.4 \mathrm{ml})$ of the treated and untreated plasma were incubated at $37^{\circ} \mathrm{C}$ for 15 minutes with $0.3 \mathrm{ml}$ of $0.15 \mathrm{M}$ phosphate buffer in saline $(p \mathrm{H} \mathrm{8})$ and with $0.3 \mathrm{ml}$ of $0.06 \mathrm{M}$ tosyl arginine methyl ester (TAMe) or benzoyl arginine methyl ester in buffer (BAMe). The reaction was then stopped by adding $0.6 \mathrm{ml}$ of $15 \%$ trichloroacetic acid. After cooling, the mixture was centrifuged for five minutes at $3000 \times g$. The supernatant was decanted off and the methanol that had been released from TAMe or BAMe hydrolysis determined spectrophotometrically, at optical density $580 \mathrm{~nm}$ using the chromotropic acid colour reagent, against methanol standards (Colman, Mattler, and Sherry, 1969c). BAMe hydrolysis was also estimated spectrophotometrically by measuring benzoyl arginine concentration at an optical density of $253 \mathrm{~nm}$. The activity of each sample was expressed as $\mu \mathrm{m}$ TAMe or BAMe hydrolyzed per millilitre plasma per hour, the prekallikrein content being the difference between the kaolin-treated and untreated samples.
The above method was also compared in samples from 16 controls and 15 patients with liver disease, with a method of measuring plasma prekallikrein by the action of kallikrein on the natural substrate. Half of the initial plasma samples were taken and further divided into two. One part was treated with kaolin, and both were then incubated with purified human bradykininogen (Brocklehurst and Mawer, 1966). The liberated bradykinin was then assayed on rat uterus and the results were expressed as kinin liberated per millilitre plasma per hour. The difference in bradykinin activity between the kaolin-treated and untreated plasma is a measure of prekallikrein content.

\section{Results}

The mean plasma bradykinogen activity of 8.55 (SD 2.60) $\mu \mathrm{g}$ per $\mathrm{ml}$ in the normal subjects studied was not significantly different from that of 8.08 (SD 3.42) $\mu \mathrm{g}$ per $\mathrm{ml}$ found in the 25 hospitalized patients with non-hepatic disorders. In the 30 cirrhotic patients, plasma bradykininogen levels were either below or in the lower half of the normal range (Fig. 1). The mean level for the group of 3.13 (SD 1.77) $\mu \mathrm{g}$ per $\mathrm{ml}$ was significantly lower than that in the normal subjects and hospital controls ( $n$ 78, $t$ $3 \cdot 16, \mathrm{P}<0.005$ ). Similar reductions in plasma bradykininogen were observed in the main aetiological subgroups of the patients with liver disease as in the complete group. The majority of those with cryptogenic, alcoholic, or biliary cirrhosis showed evidence

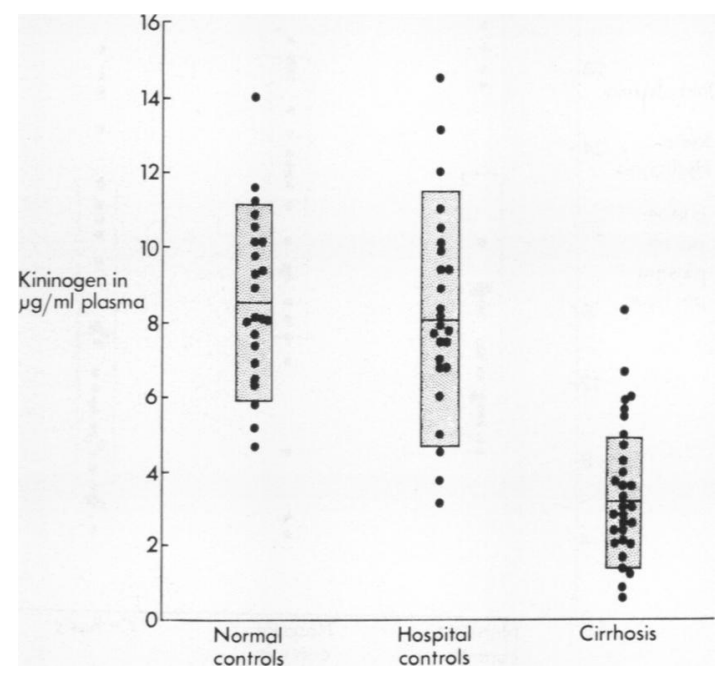

Fig. 1 Plasma bradykininogen levels in control groups and in patients with cirrhosis. 


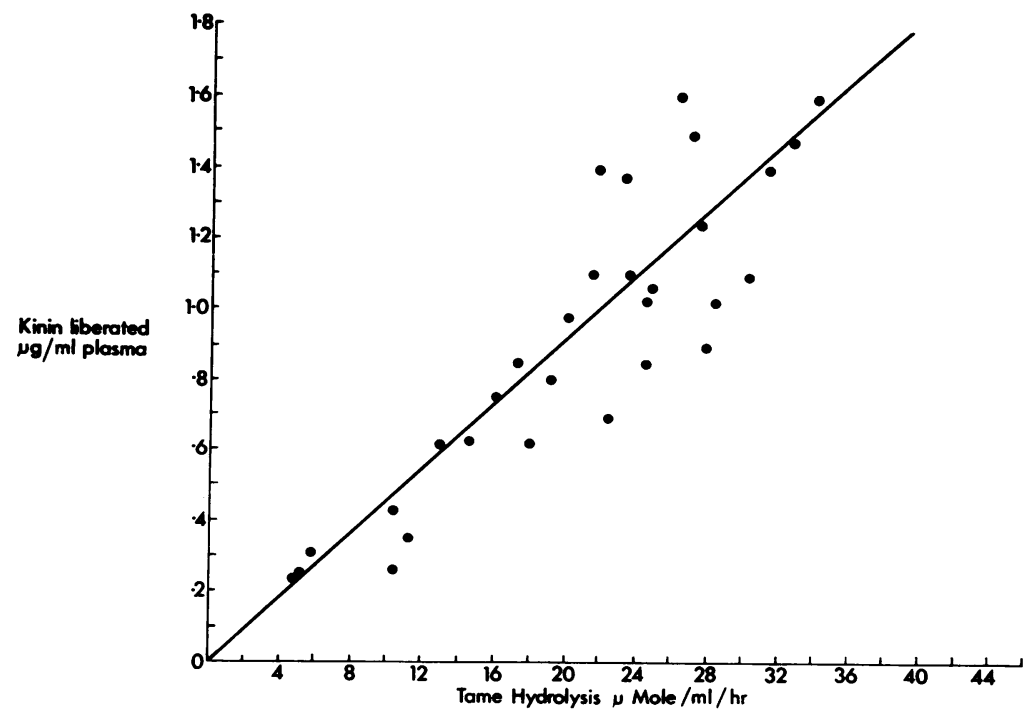

Fig. 2 Plasma prekallikrein levels measured by esterase activity (with TAMe as substrate) compared with those obtained by $a$ \& method based on measurement of liberated bradykinin.

Fig. 3 Prekallikrein levels in control groups and patients with cirrhosis.

of peripheral vasodilatation but no correlation $\stackrel{\varrho}{\rightleftarrows}$ could be discerned between this and a reduction in plasma bradykininogen. There was also no correlation between a low plasma bradykininogen and the total plasma protein concentration or the $\alpha_{2}$ globulin level.

There was a significant correlation $(r=0.78$, $P<0.05$ ) between measurements of plasma prekallikrein using TAMe or BAMe hydrolysis throughout the entire range of values. There was also a close correlation $(r=0.88, P<0.01)$ between plasma $ᄋ$ prekallikrein values obtained by the TAMe hydrolysis method and those found when bradykinin release was specifically measured (Fig. 2), and in the follow- N ing analysis of the results only the former values will be given.

The mean plasma prekallikrein in normal subjects was 16.01 (SD 6.74) $\mu \mathrm{M}$ TAMe per ml plasma per hour, which was not significantly different from the 0 mean level of 21.35 (SD 7.16) $\mu \mathrm{M}$ TAMe per ml plasma per hour found in the hospital controls. In ? the patients with chronic liver disease there was no difference in the plasma prekallikrein between the various aetiological subgroups and with a few exceptions the levels found were within the normal range (Fig. 3). Two patients - one with active chronic hepatitis and acute arthritis, and one with haemochromatosis complicated by hepatoma-had ele- 
vated prekallikrein levels of 48 to $53 \mu \mathrm{M}$ TAMe per $\mathrm{ml}$ plasma per hour. In five patients low levels of below $6 \mu \mathrm{M}$ TAMe per ml plasma per hour were obtained. Three of these were being treated for hepatic failure but others in the series with comparable hepatocellular damage had normal prekallikrein levels. A number of the patients were on azathioprine or corticosteroid therapy, but no correlation between such therapy and the prekallikrein level could be detected.

The plasma volume was measured in 22 patients using ${ }^{125}$ I human serum albumin with multiple venous samples (Blendis et al, 1970). Raised values ( $>48 \mathrm{ml}$ per $\mathrm{kg}$ ) were found in 19 patients, these including three of the patients with a reduced plasma prekallikrein, but no direct correlation could be determined between an increase in plasma volume and either the plasma prekallikrein or bradykininogen level.

\section{Discussion}

In most previous studies plasma bradykininogen has been estimated by first releasing bradykinin and then measuring the latter from its effect, using a bioassay technique, on smooth muscle, commonly rat uterus and guinea pig ileum. The plasma levels found by Oates, Melmon, Sjoerdsma, Gillespie, and Mason (1964) in normal adults of up to $10 \mu \mathrm{g}$ per $100 \mathrm{ml}$ are of the same order as in the present control groups. The release of bradykinin from its precursor is mediated by several proteolytic enzymes of which plasmin and kallikrein are the most important with kallikrein accounting for about $40 \%$ of the total (9). The characterization of human plasma kallikrein by Colman et al (1969b and c), and, in particular, their technique of using artificial rather than natural substrates in the measurement, has enabled the prekallikrein-kallikrein system to be studied directly by biochemical assay. However, the mean value for plasma prekallikrein obtained by Colman et al (1969a) in normal adults of 97 (SD 24) $\mu \mathrm{M}$ TAMe per ml plasma per hour was greater than that which we obtained. An apparent increase in plasma arginine esterase activity could occur from contact with unsiliconized glass due to activation of factor XII (Roche e Silva, Reis, and Ferreira, 1967) or it could be due to the measurement of additional esterases. However, little hydrolysis occurred when plasma samples from the present patients were assayed with acetyltyrosine ethyl ester (ATEe), a substance not hydrolyzed by kallikrein but attacked by other esterases such as trypsin, plasmin, and thrombin. Another possible cause is a change in the level of plasma kallikrein inhibitor (Colman et al, 1969a). The latter was not measured in the present patients.
The inhibitory effect of the heparin, used as the anticoagulant in the blood samples, on kallikrein activation is unlikely to be the cause, for this is only observed in human plasma when the concentration is high (Back and Steger, 1970).

One possible explanation for the reduction in plasma bradykininogen observed in our patients with chronic liver disease is an increased rate of breakdown resulting from greater activity of the prekallikrein-kallikrein system. Once bradykinin is liberated into the plasma it is rapidly inactivated by a plasma kininase known as carboxypeptidase $\mathbf{N}$ (Erdös, Sloane, and Walker, 1964). The ultimate effect of bradykinin release into plasma is therefore dependent not only on rate of activation of bradykininogen but also on the activity of the plasma carboxypeptidase. If the latter was increased and there was an increase in rate of liberation of bradykinin in the plasma to maintain the low levels normally present there, then this could lead to a reduction in plasma bradykininogen. Dedichen and Vystyd (1969) have reported an increased plasma kininase activity in acute hepatitis; this was completely inhibited by EDTA whereas the kininase present in the liver cells, which might have been released into the plasma as a result of the liver damage, is not. However, Erdos and colleagues (1964) found low plasma kininase levels in patients with cirrhosis, but, since the spleen constitutes one of the major sites of tissue carboxypeptidases (Greenbaum and Yamafuji, 1966), and since the spleen is often enlarged in cirrhosis, increased degradation of bradykinin might be occurring there rather than in the plasma. Nevertheless, if the low plasma bradykininogen were related to increased bradykinin formation then a decrease in plasma prekallikrein would be expected, as is usually found with increased activity of the prekallikrein-kallikrein system. The finding of normal prekallikrein levels in the majority of the present patients is evidence against such a mechanism.

An alternative explanation for the low plasma bradykininogen is decreased synthesis. The liver is thought to be the main site of bradykininogen synthesis and partial hepatectomy in rabbits is followed by a fall in the plasma level (Diniz and Carvalho, 1963). Chronic liver disease could impair synthesis, although there was no correlation in the present patients between the plasma levels of bradykininogen and the other plasma proteins. The experimental observations that hepatectomy or carbon tetrachloride administration also decreases the plasma prekallikrein level in animals (Werle, Vogel, and Kaliampetsos, 1963) is consistent with other evidence indicating that prekallikrein is formed in the liver (Webster, 1968). Colman and colleagues 
(1969a) found a low plasma prekallikrein level in six patients with cirrhosis and normal levels in three patients with obstructive jaundice. However, Carretero and colleagues (1970) found no significant change in blood kinins or in plasma kininogenase activity in five patients with liver failure due to cirrhosis and only five $(16 \%)$ of the patients in the present series had low levels.

Most of the current evidence therefore points to decreased hepatic synthesis of bradykininogen as the main cause of the low plasma levels rather than increased activation of the prekallikrein-kallikrein system, but doubt is likely to remain until all aspects of the activation of plasma bradykininogen and prekallikrein and of the subsequent inactivation are studied in each patient. However, the development of Talamo, Haber, and Austen (1969) of a specific and sensitive immunoassay for plasma bradykinin should facilitate further studies of the kinetics involved.

We are grateful to Dr G. P. Lewis for mich helpful advice. The Medical Research Council and King's College Hospital and the Medical School Research Trust gave generous support.

\section{References}

Back, N., and Steger, R. (1970). Effect of heparin on the kinin-forming activity of trypsin, plasmin and various kallikreins. Proc. Soc. exp. Biol. (N.Y.), 133, 740-743.

Blendis, L. M., Ramboer, C., and Williams, R. (1970). Studies on the haemodilution anaemia of splenomegaly. Europ. J. clin. Invest., $1,54-64$.

Brocklehurst, W. E., and Mawer, G. E. (1966). The purification of a kininogen from human plasma. Brit. J. Pharmacol., 27, 256-276.

Carretero, O. A., Nasjletti, A., Inon, A., and Dohmen, R. S. (1970).
Kinins, kininogen and kininogenase activity in pregnancy and hepatic failure. Amer. J. med. Sci., 259, 182-186.

Colman, R. W., Mason, J. W., and Sherry, S. (1969a). The kallikreinogen-kallikrein enzyme system of human plasma. Assay of components and observation in disease states. Ann. intern. Med., 71, 763-773.

Colman, R. W., Mattler, L., and Sherry, S. (1969b). Studies on the prekallikrein (kallikreinogen)-kallikrein enzyme system of human plasma. I. Isolation and purification of plasma kallikreins. J. clin. Invest., 48, 11-22.

Colman, R. W., Mattler, L., and Sherry, S. (1969c). Studies on the of prekallikrein (kallikreinogen)-kallikrein enzyme system of human plasma. II. Evidence relating the kaolin-activated $\vec{O}$ arginine esterase to plasma kallikrein. J. clin. Invest., 48, 23-32.

Dedichen, J., and Vystyd, J. (1969). Kininase activity of plasma from patients with arteriosclerosis, diabetes and hepatitis. Scand. J. clin. Lab. Invest., 24 (Suppl. 107), 125-127.

Diniz, C. R., and Carvalho, I. F. (1963). A micromethod for determination of bradykininogen under several conditions. Ann. N.Y. Acad. Sci., 104, 77-89.

Erdös, E. G., Sloane, E. M., and Walker, I. M. (1964). Carboxypeptidase in blood and other fluids. I. Properties distribution and partial purification of the enzyme. Biochem. Pharmacol., 13, 893-905.

Greenbaum, L. M., and Yamafuji, K. (1966). The in vitro inactivation of and formation of plasma kinins by spleen cathepsins. Brit. J. Pharmacol., 27, 230-238.

Lewis, G. P. (1960). Active polypeptides derived from piasma proteins. Physiol. Rev., 40, 647-676.

Oates, J. A., Melmon, K., Sjoerdsma, A., Gillespie, L., and Mason, $\vec{\bullet}$ D. T. (1964). Release of a kinin peptide in the carcinoid $N$ syndrome. Lancet, 1, 514-517.

Rocha e Silva, M., Reis, M. L., and Ferreira, S. H. (1967). Release of kinins from fresh plasma under varying experimental conditions. Biochem. Pharmacol., 16, 1665-1676.

Talamo, R. C., Haber, E., and Austen, K. F. (1969). A radioimmunoassay for bradykinin in plasma and synovial fluid. J. Lab. clin. Med., 74, 816-827.

Webster, M. E. (1968). Human plasma kallikrein, its activation and pathological role. Fed. Proc. 27, 84-89.

Werle, E., Vogel, R., and Kaliampetsos, G. (1963). In Proceedings of the Second World Congress of Gastroenterology, Munich, 1962, edited by E. Schmid, J. Tomenius, and G. Watkinson, p. 788. Karger, Basle. 